\title{
ALUÍSIO AZEVEDO: UM TRAPEIRO, ENTRE EÇA DE QUEIRÓS E MACHADO DE ASSIS
}

\author{
ALUÍSIO AZEVEDO: A "TRAPEIRO" \\ BETWEEN EÇA DE QUEIRÓS AND \\ MACHADO DE ASSIS
}

Monica Figueiredo ${ }^{*}$

\section{RESUMO}

Entre o "realismo" de Eça e a "modernidade" de Machado, há o imenso silêncio dedicado à obra de Aluísio Azevedo que, muito antes de Lima Barreto ou de João do Rio, foi capaz de transformar a cidade do Rio de Janeiro num cenário a ser (re)construído pelas linhas de sua ficção, testemunha da existência de uma cidade que seria posta abaixo pelo futuro governo higienizador de Pereira Passos. Este ensaio pretende problematizar a diferença e/ou o deslocamento inscritos na ficção de um autor que fez da geografia urbana um obsessivo tema.

PALAVRAS-CHAVE: Aluísio Azevedo; Realismo; geografia cultural; .

\begin{abstract}
Between Eça’s "realism" and Machado's "modernism", there is a great silence dedicated to the literary work of Aluísio Azevedo. Even before Lima Barreto and João do Rio, Azevedo was able to take the city of Rio de Janeiro as a landscape to be transformed by his work of fiction, which witnesses the existence of a city that would be destroyed by the future hygienist government of Pereira Passos. This essay will present the difference and the dislocation expressed in the work of an author for whom the urban geography is an obsessive theme.
\end{abstract}

KEYWORDS: Aluísio Azevedo/Eça de Queirós; realism; cultural geography; difference and dislocation. 
Eduardo Lourenço, num lance de genialidade e roubando Alberto Caeiro, certa vez definiu: "Eça viu como um danado" (LOURENÇO, 1997, p. 713). A expressão de impacto aparece num texto do final dos anos 90, no qual o ensaísta discute a relação mantida por Eça de Queirós com o tempo, defendendo que poucos autores estabeleceram com o devir histórico uma comunicação tão marcada pela modernidade. Eça viu como um danado e, embriagado de realidade, produziu uma obra que se firmou como incontornável ao vencer as barreiras nacionais e temporais que muitas vezes podem decretar uma metafórica morte para autoria. Vencer o esquecimento e se tornar memória são desejos inscritos na trajetória de todo autor que sabe que é somente pelo discurso que a sobrevivência pode ser preservada.

Para além de manter uma relação mimética com a realidade (como desejava a escola realista que o autor de Os Maias ajudou a fundar no Portugal dos oitocentos), Eça cedo percebeu que, muito mais do que narrar sobre aquilo que acontecia, a literatura deveria atentar para todo um universo de coisas que escapavam ao olhar comum, mas que, sorrateiramente, inscreviam uma vida condenada à dolorosa fugacidade. A literatura para Eça de Queirós era uma forma de antídoto que se opunha à inevitável morte que existe sempre e depois de tudo.

Eça nunca duvidou da inexorabilidade do tempo, esse contínuo escoar que comprova a fragilidade da vida inscrita sem retoques nas doenças dos corpos, na morte dos desejos, nos fracassos inconfessáveis, na velhice inevitável, no apego irascível às formas engessadas da tradição, no policiamento do novo, nos discursos esvaziados, nos defeitos inconfessáveis e na interdição sexual. Por isso, "de todos os grandes homens da geração de 70, ninguém teve como Eça um sentimento tão visceral, carnalmente vivo, da inanidade da vida" (LOURENÇO, 1997, p. 711). Adiantando as lições que os teóricos do discurso fariam quase um século depois, o autor de $O s$ Maias intuiu que somente a linguagem pode vencer a morte ao permanecer como discurso. Como genial artista de seu tempo, ele pretendeu salvar a vida escrevendo o esplendor do mundo visível corroído pela certeza do fim. É com sua obra que "[...] melhor se apreende que espécie de realismo é o seu e que monstro teve de vencer ou contra quem lutou para subtrair justamente a realidade - a vida real - a essa força de dissolução e de desilusão que é o Tempo." (LOURENÇO, 1997, p. 711, grifos do autor.)

Escrever é poder lembrar, é de certa forma testemunhar aquilo que o tempo insistentemente deseja apagar ou esquecer. Disto nunca duvidou Eça de Queirós, e por isso ele (prefiro sem o pronome) foi capaz de abrir espaço em seus livros para a existência de personagens de papel que, por pequenez, medo, incompetência, ou simplesmente por assumida canalhice, jamais teriam seus nomes inscritos. Eça não foi autor de grandes heróis, é de uma heroicidade falhada que sua obra se ocupa, mostrando antes mesmo da corrente da Nova História -, que, além do mundo dos vencidos, há o dos que não merecem reconhecimento, e este também carece de atenção e de registro. A respeito de Eça, Silviano Santiago já disse que suas 
personagens "querem experimentar o que falta quando algo está sobrando" (2004, p. 198), pois é de dentro de uma enorme escassez que as criaturas de papel irão reclamar, lúcida ou caricatamente, do excesso de contenção que as soterra.

Se é fato incontestável que muitos dos romances oitocentistas promoveram a exaltação dos valores imperiais e propagaram as razões colonialistas, também é verdade que outros tantos autores ataram a sua escrita ao desejo de desvelar os verdadeiros motivos e a violenta ação promovida tanto por uma burguesia industrial e expansionista quanto por uma de sustentação agrária e escravocrata, que desprezavam a diferença e que tinham como único deus o lucro. É em autores como Baudelaire, Dostoiévski, Flaubert, Leopoldo Alas (El Clarín), Machado de Assis, Eça de Queirós e - no caso específico que aqui me interessa -, Aluísio Azevedo, que se encontram "as designações mais irônicas do burguês como um ser desmemoriado, uma pessoa que recalcou, com maior ou menor sucesso, a culpa do passado" (OEHLER, 2004, p. 69), dividindo com o tédio um presente opaco e vazio.

Mas, se os principais personagens dessa galeria de criadores quiseram ou tentaram recusar, com maior ou menor sucesso, a culpa do passado, as cidades, as ruas e as casas que lhes serviram de abrigo são provas irrefutáveis de que o espaço erguido pela ficção é um reduto preservador da memória. Se o Ramalhete construído pela pena de Eça de Queirós em Os Maias é a memória sobrevivente de uma família fadada à esterilidade, numa Lisboa então remapeada pelo aparecimento da Avenida da Liberdade; e a confeitaria do Custódio em Esaú e Jacó é um cenário capaz de abrigar a dúvida e a incredulidade que a manutenção do Império ou a proclamação da República despertavam na gente simples, preocupada apenas em sobreviver diante de uma realidade que não lhes oferecia nenhuma segurança, é porque, em ambos os casos, o espaço surge como ponto crucial, já que extremamente crítico, na estrutura do melhor romance realista.

Este ensaio nasce como decorrência de um trabalho de pesquisa iniciado pela análise do romance de Eça de Queirós² e mais tarde desdobrado numa averiguação comparativa que pretendeu reunir a narrativa queirosiana à de Machado de Assis ${ }^{3}$. Creio que entre estas obras há muito mais semelhanças do que as já exaltadas diferenças que separam, em vez de unir, dois grandes escritores de um mesmo tempo histórico e herdeiros de um passado sociocultural comum. Defendo que os grandes escritores agrupados sob a égide do Realismo oitocentista, enfim, todos aqueles que para além de seu tempo permaneceram não subjugaram o trabalho artístico às exigências fotográficas que muitas vezes a escola literária defendera em seus exacerbados manifestos. Eles nunca duvidaram - já então - de que a realidade (é) seja inapresentável, porque dela o que sobrevive é a sua recriação em discurso, recriação que barthesianamente responde pelo nome de literatura. 
Três anos antes de sua morte, ocorrida em 1913, Aluísio Azevedo, numa das últimas visitas que fez ao Rio de Janeiro, em férias de sua atuação consular na capital argentina, desabafa a Coelho Neto, antigo amigo de juventude e de boêmia: "A cidade fulgurante, que hoje tenho diante dos olhos, parece-me a capital de outro país que não o meu, aquele em que me fiz e cujas almas conheço [...]. O meu tempo morreu. A velha cidade caiu com a picareta, o romancista com a desilusão!" (apud MÉRIEN, 1988, p. 332). A melancólica afirmativa partia da boca de um homem de 54 anos, afastado do Rio de Janeiro e da vida literária desde 1896, quando foi obrigado, como muitos dos escritores nacionais, a abandonar a cena literária em prol da segurança de um emprego público. Os tempos haviam mudado e a literatura também. De tal modo, que boa parte da crítica hoje acredita que, excetuando a prosa elegante e aburguesada de um João do Rio e a contundente e irônica ficção de Lima Barreto, a literatura produzida na capital da República se tinha afrancesado de tal maneira, que competentemente representava o desejo estético e higiênico que moldou a cidade do Rio de Janeiro a partir da primeira década do século XX.

Se a partir dos anos setenta do século XIX, Aluísio Azevedo tinha colhido da paisagem carioca o motivo para boa parte de seus romances não esquecendo suas crônicas e caricaturas -, a cidade que ele reencontrava em 1910 era aquela que havia sido erguida pelo desejo de embelezamento do governo de Rodrigues Alves e, mais especificamente, pelo discurso urbanístico posto em prática pela prefeitura de Pereira Passos. Sem a "velha cidade [que] caiu com a picareta”, a pena de Aluísio Azevedo também cairia. Ironicamente, o romancista que expusera em suas linhas ficcionais a cidade que Pereira Passos quis esconder morreria no mesmo ano do prefeito do bota-abaixo, afastado do país e da popularidade que por certo tempo o fez ser um dos poucos escritores de profissão que o Brasil daquele tempo conheceu. Profeticamente, em 1910, Aluísio Azevedo definiria o seu futuro e o da geração a que pertenceu:

Nós somos o arvoredo da floresta que foi desbravada. Que venham as árvores do parque, as plantas finais da civilização, os representantes do novo Templo. [...] Nós, meu caro, queres tu saber... vamos tomar um bonde que nos leve a alguma das ruas do antigo Rio, onde talvez encontremos sombra do passado. O que é verdade, meu caro, é que eu tenho saudade. (apud MÉRIEN, 1988, p. 236)

E o "novo Templo" - ironicamente referido por Aluísio Azevedo - foi erguido de maneira draconiana em menos de meia década, com a clara intenção de limpar a paisagem de qualquer "arvoredo de floresta", para que se pudessem plantar por cima as "árvores do parque, as plantas finais da civilização", obedecendo ao regime do custe o que custar. No entanto, não se pode negar a sedução que até hoje a figura de Pereira Passos exerce no imaginário nacional, haja vista a quantidade de trabalhos desenvolvidos - oriundos de várias instâncias do saber -, que arrolam direta ou indire- 
tamente seus discursos, ações ou diretrizes de governo. A verdade é que o Rio de Janeiro que Pereira Passos recebeu de herança do Segundo Império e dos primeiros anos da República era o resultado direto de uma ocupação indiscriminada e espontânea, responsável pelo desenho de uma cidade que só pode ser chamada assim depois da chegada da Família Real ao Brasil.

A cidade colonial do início do século XIX mantinha-se preservada ainda na década de 70 - época em que Aluísio Azevedo chega ao Rio pela primeira vez, vindo de São Luís do Maranhão -, tendo a sua situação agravada pelas desigualdades sociais e pela precariedade dos serviços que agora abarcavam uma população fortemente mestiça que não parava de crescer. E se, nos anos 70, Aluísio Azevedo começava sua carreira nos jornais cariocas como caricaturista, atacando os valores escravagistas e uma monarquia complacente e minada pelo clientelismo, Pereira Passos aprendia com a Paris de Haussmann o jeito de transformar a cidade num texto simbólico que guardava, em suas largas avenidas, em seus orgulhosos boulevards, em seu traçado reto, em sua arquitetura triunfalista, a mensagem que, a partir de então, não poderia ser esquecida: o mundo burguês caminhava em direção ao futuro e ao progresso, não importando quantas barricadas tivesse de sepultar ou destruir. Entretanto, Pereira Passos teria de esperar até a virada do século para tropicalizar o projeto do prefeito francês, como tão bem definiu (não sem ironia!) a análise de Jaime Larry Benchimol, em Pereira Passos: um Haussmann tropical.

"Dentro desta cidade em que estamos, há outras pequenas cidades que ninguém vê, a não serem seus moradores", escrevia um cronista anônimo na Gazeta de Notícias do Rio de Janeiro, em 1876. Essas cidades invisíveis sobreviviam na forma de cortiços, de casas de cômodos, de estalagens, de zungas, ou de melhoradas casas de pensão, ou repúblicas estudantis e assustavam a sociedade monárquica, que começava a sentir os abalos de uma abolição inevitável e o rumor republicano encabeçado pelas elites oligárquicas de cultura cafeeira. Na verdade, a cidade que Pereira Passos em seu mandato vai desconstruir foi cuidadosamente recriada pelas linhas ficcionais de Aluísio Azevedo, transformando a sua obra romanesca num precioso registro daquilo que nossa contemporaneidade chamará de "cidade partida".

Abrindo espaço para as existências marginais, o romance de Aluísio Azevedo, mesmo que de perto influenciado pelos valores positivistas tão em moda na época, foi sensível na percepção da cidade como um organismo vivo, que, obrigado a constantes refigurações, sempre foi visto pelas instâncias de poder como algo a ser dominado, higienizado, embelezado, contido e, se não restasse outra escolha, eliminado em nome daquilo que se convencionou chamar de bem público, que afinal protegia os interesses privados das elites aburguesadas postas no poder depois da queda do Império.

Recuperados pela ficção naturalista da segunda metade do século XIX, os milhares de habitantes desabrigados do sonho burguês, os deslocados das promessas de progresso que vagavam pelo Rio de Janeiro oitocen- 
tista ganham primeiro abrigo através da obra ficcional de Aluísio Azevedo, para só mais tarde, no início do século XX, conseguirem protagonizar os registros burocráticos, ao reclamarem para si um lugar que a história oficial reiteradamente lhes negou. Transformados em estatísticas pelos governos da recente República, autuados pelos livros de prisão, deportados à força de suas casas e depois exilados da cidade, os "quebra-lampiões", os revoltados da vacina, os queixosos do "bota-abaixo" são a prova irrefutável de que a individualidade conseguida em ficção, historicamente, foi posta a perder quando envolveu com o anonimato o percurso dos muitos que foram abatidos pelos desmandos autoritários de um governo que desejou transformar o Rio de Janeiro numa cidade-cenário de romance burguês, ironicamente, legando à ficção o trabalho de erguer moradas (im)possíveis, onde gente - embora de papel - pudesse viver.

Maurice Halbwachs afirma que "não é por má vontade, antipatia, repulsa ou indiferença que a memória coletiva esquece uma quantidade tão grande de acontecimentos e de antigas figuras. É porque os grupos que dela guardavam a lembrança desapareceram" (1990, p. 88). Creio que através da obra de Aluísio Azevedo é possível recolher o que de memória coletiva ficou inscrita (ao menos em ficção!), por acreditar que só assim os muitos que desapareceram - sejam eles homens e mulheres do povo, escritores ou prefeitos - poderão continuar em vida.

Com a obra inultrapassável do geógrafo brasileiro Milton Santos, aprendemos que o lugar, mais do que uma localização geográfica, é a extensão de um acontecer solidário, "entendendo-se por solidariedade a obrigação de se viver junto" (ABREU, 1998, p. 82). Disto decorre a certeza de que "o lugar é então o locus do coletivo, do intersubjetivo", onde resiste uma memória compartilhada, solidária, pois "a memória de um lugar, a memória de uma cidade, é, portanto, uma memória coletiva” (ABREU, 1998, p. 78). Unindo o discurso ficcional de Aluísio Azevedo ao discurso urbanístico de Pereira Passos está um lugar, ou antes, a cidade do Rio de Janeiro do final do Segundo Império e do início da Primeira República, ponto nevrálgico que reuniu uma infinidade de memórias individuais que, juntas, formaram o que Milton Santos chamou de memória coletiva. Se é verdade que muito desta memória se perdeu, também é possível pensar que a memória individual impressa na ficção de Aluísio Azevedo foi capaz de anunciar a mutação que a cidade oitocentista sofreria a partir dos primeiros anos do século $\mathrm{XX}$, quando se tornou um palco agitado, um cenário problematizado, onde experiências diversas e conflituosas construíram uma traumática memória coletiva, que nem os monumentos erguidos em nome da celebração histórica de supostas vitórias conseguiram silenciar.

Evitando apenas culpabilizar o governo de Pereira Passos pelos seus inquestionáveis desmandos, pretendo entender por que eles aconteceram e de que forma ficaram inscritos na memória coletiva que acompanhou a experiência da cidade. É claro que grande parte dessa memória compartilhada que se formou na virada do século passado ganhou registro 
através dos documentos e dos monumentos oficiais, pois, "quando a memória de uma sequência de acontecimentos não tem mais suporte de um grupo", "então o único meio de salvar tais lembranças é fixá-las por escrito em uma narrativa seguida, uma vez que as palavras e os pensamentos morrem, mas os escritos permanecem" (ABREU, 1998, p. 80). Ainda hoje, o centro do Rio de Janeiro guarda a "narrativa seguida" criada pelo discurso urbanístico de Pereira Passos, que, monumentalizado, se transformou em memória histórica.

Por outro lado, ao abrir espaço em sua obra ficcional - produto de sua memória individual - para que outras tantas vidas pudessem compartilhar a experiência de um mesmo lugar, Aluísio Azevedo cria uma espécie de ficção da memória coletiva, que recusa a inteireza do discurso, firmando-se como um exercício em linguagem que, mais do que afirmar, deseja sugerir. Assim, interessa reunir essas duas formas de registro da memória, contrapô-las, interrogá-las, fazer com que juntas possam de maneira dialética criar uma nova memória que, coletivamente, reúna num mesmo lugar a cidade construída pelo discurso ficcional de Aluísio Azevedo e a cidade desconstruída pelo discurso urbanístico de Pereira Passos.

Ressalvo, no entanto, que gostaria de ultrapassar o mau uso que já se fez da narrativa de Aluísio Azevedo, reiteradamente utilizada como exemplo "documental" da história do fim dos oitocentos no Brasil. Seus romances são, antes de tudo, objetos estéticos, e é assim que devem ser tratados. Há aqui desejo de desestigmatizar a obra de um autor que não raras vezes foi considerado preconceituoso, menor, protocolar, ou até mesmo um mero plagiador da obra de Eça de Queirós. Talvez já seja hora (cem anos após a sua morte) de definir o caráter estritamente literário que sua obra tem, destacando o seu trabalho com a linguagem, os recursos estilísticos de que se serviu, a forma particular de estruturação de muitas de suas narrativas e as suas competentes alegorias, capazes de refutar a etiqueta redutora de escritor-escolar do Naturalismo brasileiro com que muitas vezes ele foi catalogado. A verdade é que, para mim, um autor que foi capaz de criar enredos tão geniais e rocambolescos como o de O mistério da Tijuca; de fundar o romance policial brasileiro, usando o Rio de Janeiro de cenário, como em Mattos, Malta ou Matta?; e de assinar romances tão ideologicamente modernos para o conservadorismo de sua época, como O livro de uma sogra, é um autor que no mínimo exige urgente revisão crítica.

Por último, gostaria de pilhar de João do Rio a interessante definição que faz ao apresentar um dos muitos indigentes que vagavam pelas ruas do Rio à procura de um modo de sobreviver - refiro-me aos trapeiros cariocas que são assim agrupados pelo sensível olhar de seu narrador:

[...] os primeiros [trapeiros das fábricas de papel] apanham trapos, todos os trapos encontrados na rua, remexem o lixo, arrancam da poeira e do esterco os pedaços de pano, que serão em pouco alvo papel; os outros [trapeiros das fábricas de móveis] têm o serviço mais especial de procurar panos 
limpos, trapos em perfeito estado, para vender aos lustradores das fábricas de móveis. As grandes casas desse gênero compram em porção a traparia limpa. (2005, p. 78$)$

Como Walter Benjamin mostrou em seu instigante estudo sobre a Paris baudelairiana, são essas figuras anônimas e marginalizadas que colhem do chão das ruas os fiapos da história que só sobrevive como ruína, fragmento, ou memória esgarçada no vão das cidades. Guardadas as devidas proporções e usando a imagem do trapeiro como metáfora, quero crer que Aluísio Azevedo transformou aquilo que viu no papel onde ficcionalmente inscreveu a realidade que o circundava; do mesmo modo que foi a feiura e o horror presentes no Rio de Janeiro de seu tempo que despertaram, em Pereira Passos, o desejo de lustrar uma paisagem que exigia urgente transformação. Trapeiros distintos de uma cidade pretensamente igual.

Se, por um lado, o projeto draconiano que marcou a gestão de Pereira Passos trouxe para o Rio de Janeiro dos primeiros anos do século $\mathrm{XX}$ a sensação inebriante de que o futuro vinha para ficar e que, em nome dele, quase tudo seria permitido, é certo que Aluísio Azevedo percebeu a voragem dos dias ainda nos últimos anos do século XIX, quando fez de sua Bertoleza um tosco cordeiro de deus, enviezadamente posto em sacrifício, em nome da ascensão burguesa de um João Romão, inconformado na sua condição de emigrante, determinado a não ocupar o lugar do cativo, justo num país escravocrata que nenhuma Lei Áurea iria redimir. A violência social que lhe saltava aos olhos provocou a agudeza na percepção da realidade, garantiu o questionamento dos valores burgueses - mesmo que embaralhados em nossa particularíssima herança latifúndio-colonial! Cansado "das plantas finais da civilização", Aluísio Azevedo abriu mão do trapo/papel e, como trapeiro desempregado, deixou de escrever.

\section{REFERÊNCIAS BIBLIOGRÁFICAS}

ABREU, Maurício de Almeida. Sobre a memória das cidades. In: Revista da Faculdade de Letras - Geografia I, vol. XIV. Porto: Universidade do Porto, 1998, p. 77-97.

BENCHIMOL, Jaime Larry. Pereira Passos: um Haussmann tropical. Rio de Janeiro: SMCTT, 1990.

BENJAMIN, Walter. Charles Baudelaire: um lírico no auge do capitalismo. São Paulo: Brasiliense, 1989.

CHALHOUB, Sidney; PEREIRA, Leonardo Affonso de Miranda. A História contada: capítulos de história social da literatura do Brasil. Rio de Janeiro: Nova Fronteira, 1998.

FIGUEIREDO, Monica. No corpo, na casa e na cidade: as moradas da ficção. Rio de Janeiro: Língua Geral, 2011.

De vencedores vencidos: Machado \& Eça num encontro. Manaus: Editora da UEA/ FAPEAM, 2013.

HALBWACHS, Maurice. A memória coletiva. São Paulo: Vértice, 1990.

LIMA, Isabel Pires de. O tempo dos “inutensílios”: o lugar das humanidades na contemporaneidade. Porto: Universidade do Porto, 2015.

LOURENÇO, Eduardo. O tempo de Eça e Eça e o tempo. In: MINÉ, Elza \& CANIATO Benilde Justo (orgs.). 150 anos com Eça de Queirós - III Encontro Internacional de Queiro- 
sianos. São Paulo: USP, 1997, p. 707-713.

MÉRIEN, Jean-Yves. Aluísio Azevedo: vida e obra (1857-1913). O verdadeiro Brasil do século XIX. Rio de Janeiro: Instituto Nacional do Livro, 1988.

OEHLER, Dolf. Terrenos vulcânicos. São Paulo: Cosa \& Naify, 2004

RIO, João do. A alma encantadora das ruas: crônicas. São Paulo: Companhia das Letras, 2005

SANTIAGO, Silviano. O brutalista e o intimista. In: CERDEIRA, Teresa Cristina (et al.). A primavera toda para ti - homenagem a Helder Macedo. Lisboa: Editorial Presença, p. 197-200.

SANTOS, Milton. Técnica, espaço, tempo. São Paulo: Hucitec, 1994.

SEVCENKO, Nicolau. A literatura como missão - Tensões sociais e criação cultural na Primeira República. São Paulo: Brasiliense, 1983.

Recebido para publicação em 25/10/2015

Aprovado em 17/02/2016

\section{NOTAS}

* Professora de Literatura Portuguesa da Faculdade de Letras da UFRJ e pesquisadora do CNPq.

2 Listo aqui os referidos projetos de pesquisa: "No corpo, na casa e na cidade: a ficção ergue a morada possível" (1998-2002); "E[ç] as mulheres: um estudo da presença feminina na narrativa de Eça de Queirós” (2003-2007); “Eça de Queirós e o testemunho como segunda pele" (2011-2013).

3 Refiro-me ao projeto de pesquisa: "De vencedores vencidos: Bento Santiago, Carlos da Maia e D. Álvaro Mesía. Algumas considerações sobre o romance ibero-brasileiro-oitocentista" (2007-2010). 